\title{
The agglomeration of coal fines using wet microalgae biomass
}

\author{
Sibongiseni Gaqa*, Paul Watts \\ Faculty of Science, Nelson Mandela University, Summerstrand Campus, PO Box 77000, \\ Port Elizabeth 6031, South Africa
}

\begin{abstract}
South African coal generally contains a high percentage of non-carbon mineral matter, which necessitates processing to remove the bulk of the non-carbon material. Such processing results in the formation of some 60 million tons of discard coal and between four and eight million tons of very fine, unusable coal, called ultra-fines, each year. The objective of this study was to investigate factors that impact on the agglomeration of fine coal of $<150$ $\mu \mathrm{m}$ when using microalgae biomass as the sole binder. Mixtures of coal and wet microalgae biomass were prepared and pelletised. The proximate properties of the mixtures and coal were determined and the physical properties of the pellets measured, such as compression strength, water resistance and impact resistance. The results showed that pelletisation of Coalgae ${ }^{\circledR}$ is a promising technology for the recovery of coal fines. Moisture content, pressure and holding time influence the quality of the pellets. Compression resistance testing indicated that pellets made from the
\end{abstract}

coal $_{80 \%-\text { algae }_{20 \%}}$ (by weight) mixture were stronger than those made from the coal ${ }_{90 \%}$-algae $10 \%$ (by weight) mixture. Pellets made from samples with \pm $17 \%$ moisture content exhibited the strongest resistance, one of $1.8 \mathrm{~kg} / \mathrm{mm}^{2}$ for the coal $80 \%$-algae $20 \%$ mixture that was centrifuged after 24 hours. The water resistance index for all the pellets was lower than the recommended $95 \%$, which was considered to put emphasis on handling, transportation and storage of the pellets.

Keywords: Scenedesmus, Coalgae ${ }^{\circledR}$; pellets.

Journal of Energy in Southern Africa 29(2): 43-50

DOI: http://dx.doi.org/10.17159/2413-3051/2018/v29i2a3469

Published by the Energy Research Centre, University of Cape Town ISSN: 2413-3051 http://journals.assaf.org.za/jesa

Sponsored by the Department of Science and Technology

\footnotetext{
* Corresponding author: Tel: +27 41504 3688:

email: sibongiseni.gaqa@gmail.com
} 


\section{Introduction}

Coal is the most widespread fossil fuel, with more than 75 countries having coal deposits (World Energy Council, 2013), and is currently the world's second-largest source of energy supply. The share of coal-powered electricity generation is more than $40 \%$ globally, but this proportion is expected to decrease in the coming years, although the nominal amount used will increase slightly (World Energy Council, 2013). The future of coal depends primarily on the advance of clean-coal technologies to reduce environmental risk factors such as $\mathrm{CO}_{2}$ emissions (World Energy Council, 2013).

Coal has played a vital role in South Africa's economy for over a century and bituminous coal is currently the primary source of energy for electricity generation, and is also used to produce a significant part of the country's liquid fuels. It also provides a substantial source of foreign revenue from exports (Hancox and Götz, 2014). South Africa's coal reserves may be depleting, but its energy needs keep increasing. Eskom is responsible for the country's generation, transmission and distribution of electricity, supplying about $95 \%$ of the country's electricity (Eskom, 2018). The increasing demand for electricity is placing pressure on Eskom's existing power generation capacity. Coal fines have been considered uneconomic, environmentally hazardous and difficult to process, with good processing they have shown that they can be useful.

Coal fines agglomeration is not a new concept; it has been around for at least a century (River Energy SA, 2013). Agglomeration involves applying pressure onto small coal particles, with or without the addition of a binder, to form compressed or agglomerate-shaped pellets that can be used either for domestic or industrial applications. A number of studies on coal fines pelletising have been carried out; numerous researchers, such as (Borowski \& Hycnar, 2013), have indicated that there is a possibility of using coal fines based pellets as a fuel in power plants. Pelletising is a complex process that requires dealing with different types of fine grained material. There are a number of factors that need to be considered, and so it is necessary to determine these factors because they affect the pelletising process. The factors include the hardness of the material, the moisture content, and pressure, amongst others.

Coal fines agglomerates are not strong enough without the addition of the binding agent; therefore, it is necessary to alter the properties of the material, and this can be achieved by adding a binder complex. A production process on three types of coal based fuel agglomerates with additional components, such as potato starch, mollasses, and wood biomass (Borowski \& Hycnar, 2013). The resulting compound was made using a roll press unit to obtain agglomerates, which then required drying and conditioning to produce solid fuel that can be used for combustion in domestic and industrial applications.

The results showed that the agglomerates made with starch met the minimum quality requirements of the agglomerated fuel, but then the use of a cheaper binder such as molasses did not produce good quality agglomerates. Also, adding of biomass in an amount not exceeding $20 \%$ by weight did not significantly affect the pollution emissions in the combustion tests, and they obtained a fuel with suitably high energy value of 22-24 MJ.kg-1 and this fuel may be used as an alternative fuel for combustion in industrial and domestic boilers (Borowski \& Hycnar, 2013).

A technology to convert coal fines into solid lumps was introduced and patented by Easby (1848). However, the use of binding agents to hold the coal fines together has been problematic. The necessary cost of adding expensive additional elements to the coal fines results in the product being difficult to market to the end-users. The combustion profile, physical and chemical properties of the briquettes/pellets can also be different from solid coal (Energy Efficiency, 2009).

\section{Materials and methods}

The objective of the study on which this paper reports was to investigate factors that impact on the agglomeration of fine coal of $<150 \mu \mathrm{m}$ when using microalgae biomass as the sole binder. The coal used was the standard low-grade South African coal, with high ash yield, and the type of algae used is a standard pond-grown Scenedesmus microalgae, obtained from InnoVenton, an algae research institute based at Nelson Mandela University in Port Elizabeth, South Africa. It was harvested and concentrated through sedimentation.

\subsection{Coal sample preparation}

Coal was prepared using the American Society for Testing and Materials (ASTM) D2013 standard method of preparing coal samples for analysis. The cone-and-quartering method was applied after size reduction to obtain more representative samples. The coal was crushed in a Keegor vertical spindle pulveriser to approximately $\pm 250 \mu \mathrm{m}$. Laboratory test sieves were used to obtain $\mathrm{a}-150 \mu \mathrm{m}$ fraction.

\subsection{Preparation of the mixtures}

The microalgae were centrifuged on a Lasec SA HRMLE Z383 centrifuge at $4500 \mathrm{rpm}$ to obtain the slurry concentrates. The $-150 \mu \mathrm{m}$ coal fines were mixed with microalgae biomass slurry in ratios of 90:10 and 80:20 (by weight), i.e., 90\% coal:10\% wet microalgae and $80 \%$ coal: $20 \%$ wet microalgae. It was necessary to first determine the percentage fraction of total solids present in the microalgae, for the preparation of the samples. 
Total solids

Total dissolved solids are a measure of the combined amount of all the inorganic and organic substances contained in a liquid in molecular, ionised or micro-granular suspended form. Total solids were analysed as stipulated by NREL/TP-51042621, a standard method used for determining the total solids suspended in carbonaceous materials. Samples (of microalgae) in triplicate were weighed and transferred to the weighed crucibles and then placed in an oven for an hour. Then they were cooled in a desiccator to ensure that no air moisture gets inside the crucibles. Then they were weighed. The total solids of the samples were then calculated as in Equation1:

$$
\text { \%total solids }=\frac{[(\mathrm{A}-\mathrm{B})]}{\mathrm{C}} \times 100
$$

where $\mathrm{A}=$ mass $(\mathrm{g})$ of crucible with dried sample, $\mathrm{B}=$ mass ( $\mathrm{g}$ ) empty crucible and $\mathrm{C}=$ mass ( $\mathrm{g}$ ) of the sample used.

For the preparation of the samples, the amount of the required wet microalgae was calculated using Equation 2.

$$
\begin{aligned}
& \text { Mass of liquid algae needed }(\mathrm{g}) \\
& =\frac{\text { mass of dry algae }}{\% \text { total solids of algae } / 100}
\end{aligned}
$$

One sample (of each mixture) was centrifuged immediately, while the other sample (of each mixture) was left stirring and only centrifuged after 24 hours. Figure 1 shows the steps that were taken for the preparation of the mixtures.

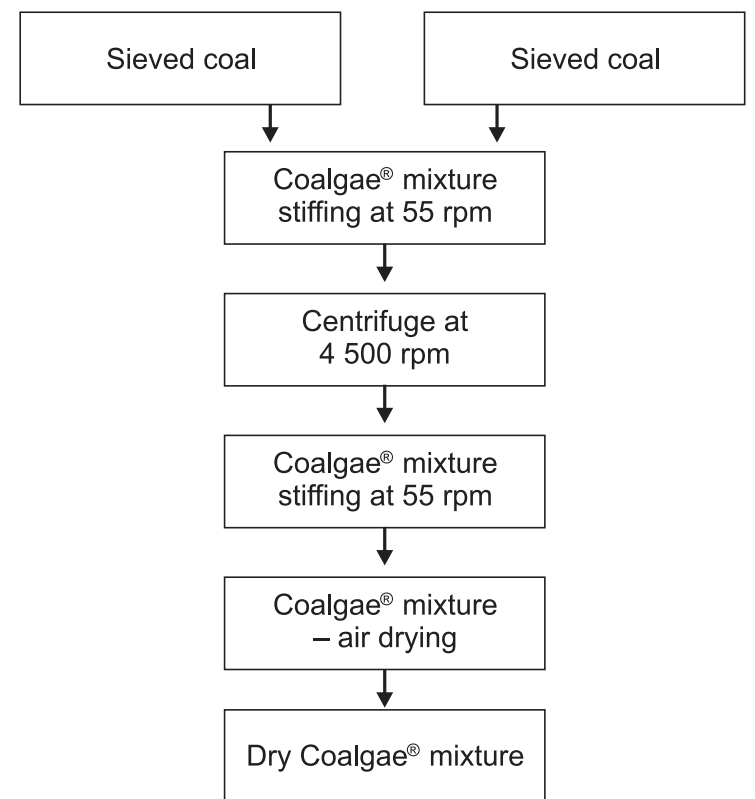

Figure 1: Preparation of coal-algae mixtures.

Coalgae ${ }^{\circledR}$ is the name given to the mixture of coal and microalgae. Proper mixing was crucial to ensure even distribution of the microalgae throughout the mixture; and this was done using an electric overhead stirrer. The samples needed to be dried after mixing because the moisture content of the microalgae is about $97 \%$, while the moisture content of the samples for pelletising must be less than $25 \%$, otherwise the sample will not hold inside the sample holder during pelletisation - it would just pass through the sides. It is also easier to store a dry sample for future use than wet or damp samples, which tend to develop fungus.

\section{Sample analysis}

Proximate analysis was carried out to determine percentage moisture content, percentage volatile matter content, percentage fixed carbon content, as well as the percentage ash yield. This analysis was necessary to establish the interrelationship when coal is mixed with microalgae. The proximate analysis was determined using an oven and a muffle furnace, using the ASTM standard methods given in Table 1.

Table 1: Methods used for the determination of proximate analysis.

\begin{tabular}{ll}
\hline \multicolumn{1}{c}{ Test } & \multicolumn{1}{c}{ Method } \\
\hline Percentage moisture content & ASTM_D3173 \\
Percentage volatile matter content & ASTM_D3175 \\
Percentage fixed carbon content & ASTM_D3172 \\
Percentage ash yield & ASTM_D3174 \\
\hline
\end{tabular}

The energy values of the materials were calculated from the proximate analysis. There are a variety of correlations for predicting higher heating value (HHV) from ultimate analysis of samples. Several correlations of $\mathrm{HHV}$ with proximate analysis have appeared in the solid fuel literature in the past, with a focus on one fuel or dependent on the country of origin. A general correlation based on proximate analysis of solid fuels to calculate HHV was introduced by Parikh et al. (2005) and was applied in the present study using Equation 3.

$$
\begin{aligned}
& \mathrm{HHV}=(0.3536(\mathrm{FC}))+() .01559(\mathrm{VM}))- \\
& (0.0078(\mathrm{ash}) \mathrm{MJ} / \mathrm{kg}
\end{aligned}
$$

where $\mathrm{FC}=$ percentage of fixed carbon and $\mathrm{VM}=$ percentage of volatile matter

The elemental analysis, which is the determination of carbon, hydrogen, nitrogen and sulphur, was carried out using a Vario EL CUBE CHNS analyser, following the international standard: ASTM_D3176; and the oxygen was determined by difference.

\subsection{Pelletising}

Pelletising of coal fines involves applying pressure to small coal particles, with or without the addition of 
a binder to form compact- or agglomerate-shaped fragments for domestic or industrial applications (Diez et al., 2013). The present study used microalgae as a binder for pelletising. Pellets were prepared from different percentages of coal-algae mixtures, using binderless coal pellets as a reference, which were also made using coal fines. The pellets were prepared using a hydraulic press with hydraulic pump under various pressures as shown in Figure 2.

The pellets were activated as soon as they get out of the press to get rid of the excess water, by placing the pellets in an oven for four hours at 105 $\pm 20{ }^{\circ} \mathrm{C}$. Mixtures with two different moisture contents were used, of $17 \%$ and $22 \%$, respectively. Different moisture contents were used to determine whether the moisture content affects the quality of the pellets. The pellets were, on average, with a diameter of $20 \mathrm{~mm}$, a height of $20 \mathrm{~mm}$, and with a mass of $8.385 \mathrm{~g}$.

The compressive strength of the pellets was determined using a Zwick/Roell extensometer at a speed of $10 \mathrm{~mm} / \mathrm{min}$. The water resistance index (WRI) was determined by immersing pellets into tap water for 30 minutes and then applying Equation 4.

$$
\text { WRI }=100-\% \text { water after } 30 \text { minutes }
$$

The downfall durability was determined indoors, by dropping the pellets on a concrete floor from a height of $1.85 \mathrm{~m}$ (Saikia and Baruah, 2013), and the impact resistance index (IRI) was calculated using Equation 5.

$$
\mathrm{IRI}=\frac{100 * N}{n}
$$

where $\mathrm{N}=$ number of drops and $\mathrm{n}=$ total number of pieces from the dropped pellet.

\section{Results and discussion}

Table 2 shows the proximate analysis of coal and Coalgae ${ }^{\circledR}$ mixtures. This analysis was necessary to see whether any physical improvements result from mixing coal fines with microalgae. The coal fines used for this study were of very poor quality, while the microalgae was a good quality biomass material, so that it was expected that mixing the two would produce an improved product when compared with the coal fines.

Table 2 indicates that volatile matter content increased in the coal-algae mixtures as compared with original coal. Biomass materials generally have a higher volatile matter content, however, it was essential to quantify the exact values for a detailed assessment. Very low volatile matter content results in the slow-burning of material during combustion. Both the ash yield and fixed-carbon content decreased in the mixtures. A decrease in ash yield is a good thing because high ash yield leads to block-

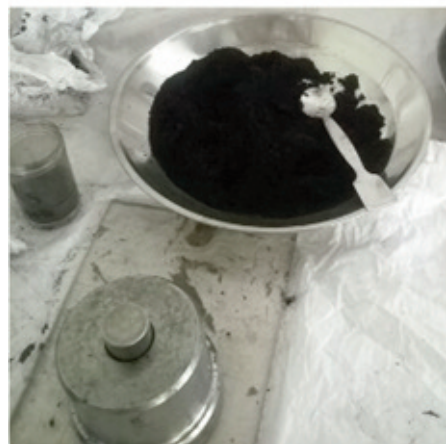

Coalgae $^{\circledast}$
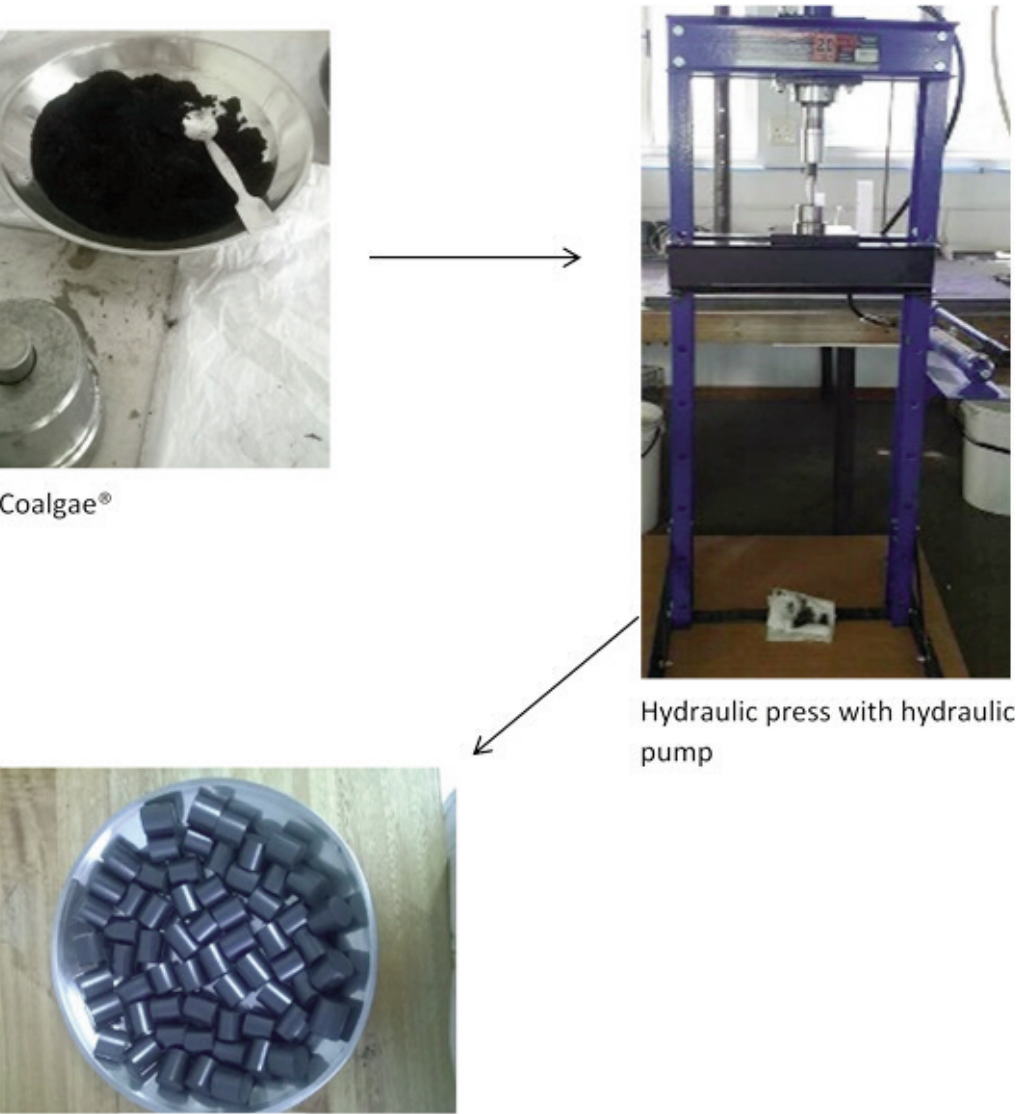

Pellets

Figure 2: Production of the pellets. 
Table 2: Proximate analysis of coal fines and coal-algae mixtures dry basis.

\begin{tabular}{|c|c|c|c|c|}
\hline Sample ID & $\%$ Volatile & $\%$ Ash & $\% F C$ & $H H V(M J / k g)$ \\
\hline Pure coal & $20.0 \pm 0.3$ & $38.6 \pm 0.2$ & 41.4 & 16.4 \\
\hline Algae & $78.0 \pm 0.4$ & $7.4 \pm 0.1$ & 14.6 & 17.3 \\
\hline Coal $_{90 \%}$-algae $10 \%$ (mixed \& centrifuged) & $25.4 \pm 0.1$ & $35.4 \pm 0.0$ & 33.9 & 16.6 \\
\hline Coal $_{80 \%}$-algae $20 \%$ (mixed \& centrifuged) & $34.0 \pm 0.1$ & $35.1 \pm 0.1$ & 25.5 & 15.1 \\
\hline Coal $_{90 \%}$-algae $10 \%$ (centrifuged after 24 hours) & $25.7 \pm 1.2$ & $35.8 \pm 0.0$ & 33.4 & 16.4 \\
\hline Coal $_{80 \%}$-algae $20 \%$ (centrifuged after 24 hours) & $34.8 \pm 0.1$ & $32.9 \pm 0.14$ & 27.8 & 15.8 \\
\hline
\end{tabular}

ages in some equipment during combustion and to lower heating values. The ash yield plays a vital role in the determination of the value of carbonaceous materials. The ash is mostly made up of the mineral matter. Generally, the higher the ash yield of coal, the lower is its value as a result of a correspondingly reduced energy content of the coal (Zeelie, 2013).

The HHV increased slightly in the coal $90 \%-$ algae $_{10 \%}$ mixtures and dropped significantly in the coal $_{80 \%}$-algae $20 \%$ mixtures, because of the lower fixed carbon content. These results show a positive response of the coal fines when mixed with wet microalgae biomass, more especially for the coal $_{90 \%}$-algae I $_{10 \%}$. The coal $_{80 \%}$-algae $20 \%$ mixture responded well to the moisture and volatile matter contents, but responded poorly to the fixed carbon content and ash yield, and the HHV. The heating value indicates the heat that can be generated when burning solid fuel.

Table 3 shows the elemental analysis results of coal and the Coalgae ${ }^{\circledR}$ mixtures to establish the chemical properties of coal and obtain the basis for comparison with the Coalgae $\AA$ mixtures, as well as to allow inferences to be drawn about the effects of blending coal with microalgae on the elemental composition of the final product.

From Table 3, it can be observed that the oxygen content of the mixtures is lower than that of coal with high carbon content. Generally, biomass materials are known to have high oxygen content and low carbon content. The carbon content of a typical biomass material is about $45 \%$, with that of coal being around $60 \%$ and more (Cai et al., 2017). This is, however, not the case with the coal and biomass that were used for this study, since the waste coal used had a carbon content of $48.10 \%$ and the algae had a carbon content of $57.80 \%$. This may have an impact on the energy value of the feedstock, but might not be a problem, as it may be complemented by the reactivity of the biomass, in this case microalgae, that would act as a catalyst for full conversion of coal, thereby resulting in more energy being released (Gaqa et al., 2014). The hydrogen content is mostly associated with volatile matter content, hence the hydrogen content of coal fines is lower than that of the mixtures. Hydrogen in the right proportion enhances the combustibility of the samples which can make Coalgae $₫$ a promising fuel.

The compression strength (also known as compressive resistance) of the pellets made from two different mixture ratios of coal and microalgae, with coal used as a reference, is shown in Figure 3. These results are of the pellets made from samples with a moisture content of 17 and $22 \%$, respectively, pressed at a pressure of 3500 psi and holding time of one minute.

Figure 3 shows that the pellets made from the coal $_{80 \%}$-algae $20 \%$ mixture with $17 \%$ moisture content are stronger than the pellets made from the same sample with $22 \%$ moisture content. The pellets made from coal $_{80 \%}$-algae $20 \%$ mixture, with moisture content of $17 \%$ had a maximum crushing load (maximum force) of $1.3 \mathrm{~kg} / \mathrm{mm}^{2}$, while the pellets that were made from the same mixture but with moisture content of $22 \%$ had a maximum crushing load of $1.1 \mathrm{~kg} / \mathrm{mm}^{2}$. The error bars show that this difference is significant. The pellets that were made from the coal $90 \%$-algae $10 \%$ mixture with $22 \%$ moisture content appeared to be stronger than the pellets made from the same mixture but with moisture content of $17 \%$. The pellets made from coal ${ }_{90 \%-}$

Table 3: Elemental analysis of coal fines and the coal-algae mixtures (dry ash free basis).

\begin{tabular}{lccccc}
\hline Sample ID & $w t \%$ nitrogen & $w t \%$ carbon & $w t \%$ hydrogen & $w t \%$ sulphur & wt \% oxygen \\
\hline Pure coal & $1.98 \pm 0.01$ & $48.10 \pm 0.47$ & $2.31 \pm 0.04$ & $0.16 \pm 0.26$ & 47.45 \\
Algae & $10.15 \pm 0.06$ & $57.80 \pm 0.22$ & $8.34 \pm 0.03$ & $0.45 \pm 0.01$ & 23.26 \\
Coalgae ${ }^{\circledR}{ }_{90: 10}$ & $1.78 \pm 0.06$ & $69.99 \pm 0.32$ & $3.01 \pm 0.09$ & $0.49 \pm 0.07$ & 24.73 \\
Coalgae ${ }^{\circledR} 80: 20$ & $3.80 \pm 0.01$ & $67.67 \pm 0.24$ & $5.60 \pm 0.11$ & $0.83 \pm 0.01$ & 22.10 \\
Coalgae ${ }^{\circledR}{ }_{90: 10}(24 \mathrm{hrs})$ & $1.85 \pm 0.11$ & $68.95 \pm 0.08$ & $2.94 \pm 0.00$ & $0.41 \pm 0.00$ & 25.85 \\
Coalgae ${ }_{80: 20}(24 \mathrm{hrs})$ & $3.71 \pm 0.04$ & $67.29 \pm 0.80$ & $5.77 \pm 0.22$ & $0.88 \pm 0.03$ & 22.35 \\
\hline
\end{tabular}




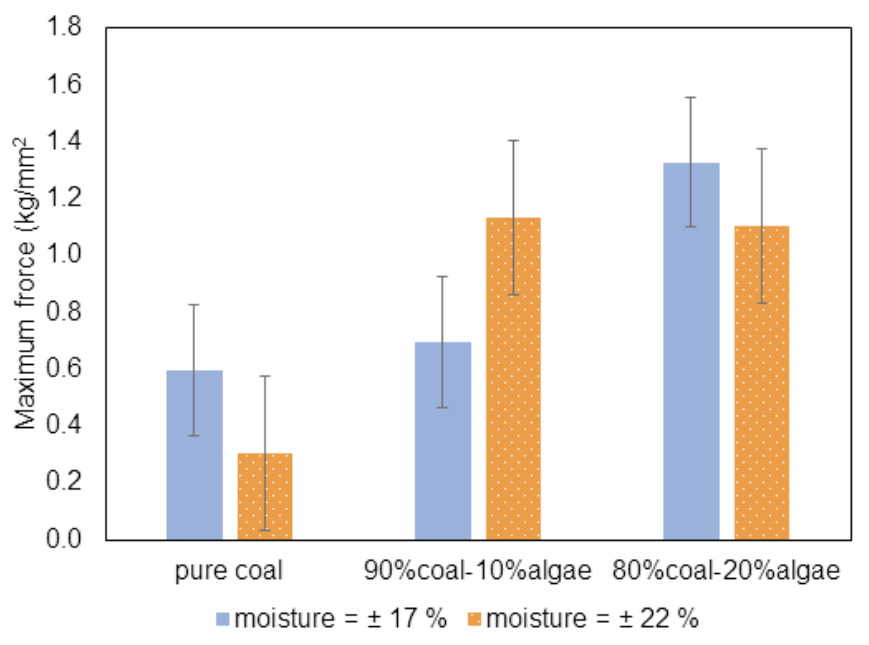

Figure 3: Compressive resistance of the pellets made from samples with moisture contents of $17 \%$ and $22 \%$, and pressure of 3500 psi for one minute.

algae $_{10 \%}$ mixture, with moisture content of $17 \%$ had a maximum crushing load of $0.7 \mathrm{~kg} / \mathrm{mm}^{2} \mathrm{com}$ pared with $1.1 \mathrm{~kg} / \mathrm{mm}^{2}$ of the pellets that were made from the same mixture but with moisture content of $22 \%$; and there was no overlapping between the error bars, which means that this difference is significant. The pellets made from the Coalgae ${ }^{\circledR}$ mixtures with the sample moisture of $22 \%$ showed no significant difference and despite efforts to use well-mixed samples. The main reason could be that some pellets made from the $\mathrm{coal}_{80 \%}$-algae $20 \%$ mixture had more cracks since the extensometer finished the test as soon as the pellet starts to crumble.

Compressive resistance of mixtures was determined after 24 hours of centrifuging of samples. Figure 4 presents the compressive resistance of the pellets made from the samples with moisture contents of $17 \%$ and $22 \%$, respectively, pressed at a pressure of $3500 \mathrm{psi}$ and held under pressure for one minute.

Figure 4 shows that the pellets made from the samples with $17 \%$ moisture content appeared to have more compression resistance than those made from samples with moisture content of $22 \%$. The pellets made from coal $_{90 \%}$-algae ${ }_{10 \%}$ mixture, with moisture content of $17 \%$, had a maximum crushing load (maximum force) of $0.7 \mathrm{~kg} / \mathrm{mm}^{2}$, while the pel-

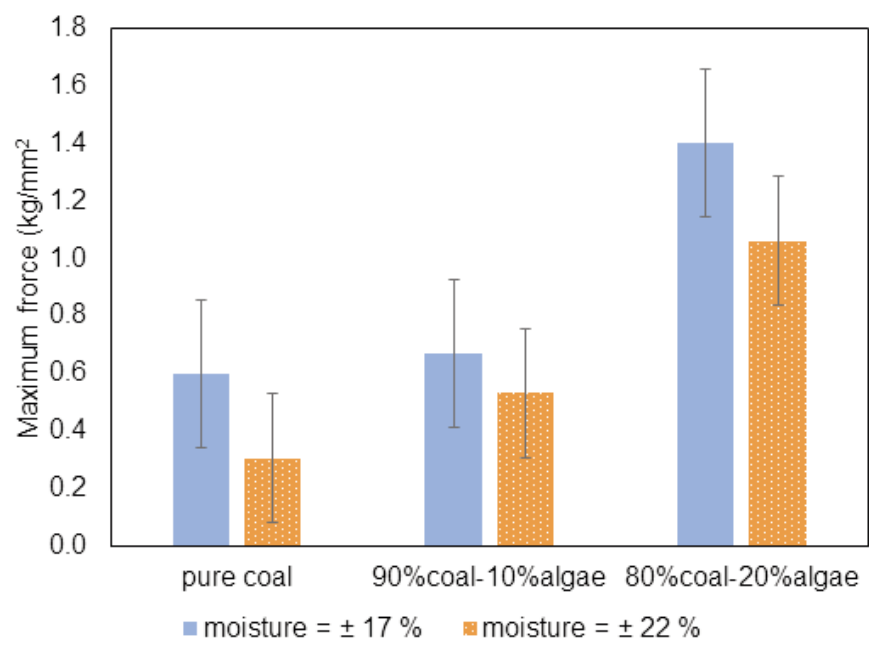

Figure 4: Compressive resistance of the pellets made from samples with moisture contents of $17 \%$ and $22 \%$, and pressure of 3500 psi for one minute.

lets made from the same mixture but with moisture content of $22 \%$ had a maximum crushing load (maximum force) of $0.5 \mathrm{~kg} / \mathrm{mm}^{2}$, and the error bars showed that there was a difference between the two.

The pellets made from coal $_{80 \%}$-algae $20 \%$ with a moisture content of $17 \%$ had a crushing load of 1.4 $\mathrm{kg} / \mathrm{mm}^{2}$ and those made from the sample with a moisture content of $22 \%$ had a crushing load of 1.0 $\mathrm{kg} / \mathrm{mm}^{2}$. The error bars also showed that this difference is significant. Richards (1990) carried out a study on briquettes using a mixture of sub-bituminous coal and starch-based binder and found compressive strength results less than $375 \mathrm{kPa}(0.038$ $\mathrm{kg} / \mathrm{mm}^{2}$ ); the conclusion was that those briquettes failed the compression test because they were expected to at least be $375 \mathrm{kPa}$, the value adopted as the benchmark for laboratory-scale work. The pellets made from Coalgae ${ }^{\circledR}$ in the present study had a compression resistance of more than 0.038 $\mathrm{kg} / \mathrm{mm}^{2}$. According to Richards (1990), a WRI greater than $95 \%$ should be obtained after $30 \mathrm{~min}$ utes. Table 3 presents the water resistance results of the pellets.

From Table 3 it can be observed that the pure coal pellets failed the water resistance test. They completely disintegrated within five minutes, having

Table 3: Water resistance index of the briquettes.

\begin{tabular}{|c|c|c|}
\hline Sample ID & $\begin{array}{c}\text { WRI at } 3500 \mathrm{psi} \\
\text { sample moisture }= \pm 17 \%\end{array}$ & $\begin{array}{c}\text { WRI at } 3500 \mathrm{psi}, \\
\text { sample moisture }= \pm 22 \%\end{array}$ \\
\hline Pure coal & 0.0 & 0.0 \\
\hline Coal $_{90 \%}$-algae $e_{10 \%}$ mix (mixed \& centrifuged) & 0.0 & 75.6 \\
\hline Coal $_{80 \%}$-algae $20 \%$ mix (mixed \& centrifuged) & 88.9 & 81.3 \\
\hline Coal $_{90 \%}$-algae $e_{10 \%}$ mix (centrifuged after 24 hours) & 75.5 & 80.5 \\
\hline Coal $_{80 \%}$-alga $e_{20 \%}$ mix (centrifuged after 24 hours) & 65.5 & 86.7 \\
\hline WRI = water resistance index & & \\
\hline
\end{tabular}


started to disintegrate within a few seconds of being submerged. The pellets made from the coal $90 \%$ algae $_{10 \%}$ mixture with sample moisture of $17 \%$ (mixed and centrifuged) also completely disintegrated in water, while those made from the coal $80 \%$ algae $_{20 \%}$ mixture (mixed and centrifuged) had a WRI of 88.9. For the samples that were centrifuged after 24 hours, however, the pellets made from the coal $_{90 \%}$-algae $10 \%$ mixture had a higher WRI, 75.5, than the 65.5 of the pellets made from the coal $80 \%$ algae $_{20 \%}$ mixture.

The pellets made from mixture samples with a moisture content of $\pm 22 \%$ showed that those made from the coal $_{80 \%}$-algae $20 \%$ mixture (mixed and centrifuged) were more water resistant, at 81.3, than other mixtures. The pellets made from the coal ${ }_{90 \%}$ algae $_{10 \%}$ mixture (mixed and centrifuged) had a WRI of 75.6, while those made from samples that were centrifuged after 24 hours had WRIs of 80.5 and 86.7 respectively. These pellets show a resistance index lower than $95 \%$ after 30 minutes in water, and would therefore not be able to handle higher humidity conditions, implying that great care would need be taken to avoid exposure to humidity as much as possible during packaging, transportation and storage.

The WRI of zero shows that the pellets have completely disintegrated in water and leaving nothing to weigh to do the calculation.

Impact resistance index

Table 4 presents the impact resistance results of the pellets. There is a difference between the two mixtures compared with coal, with the pellets made from the coal $_{90 \%}$-algae $_{10 \%}$ mixture appearing to have even stronger impact resistance than those made from the coal $_{80 \%}$-algae $20 \%$.

It can be inferred that this is not a bad thing, since producing pellets from $80 \%$ coal $20 \%$ microalgae mixture would not be ideal because of the cost implication of using more microalgae. The amount of moisture present in the samples used for pelletising significantly affected the impact resistance of the pellets; the lower the better. According to Richards (1990), an IRI of 50 was adopted as the lowest acceptable value for the development of fuel pellets. All the pellets in the present study have a higher IRI than this benchmark.

\section{Conclusions}

Densification of materials into pellets reduces challenges such as handling, transportation and storing. Mixing coal and algae biomass to improve the properties of waste coal could be a promising technology. Extra care needs to be taken, however, to form good quality pellets when mixing the two materials and choosing the parameters with which to work. During pelletisation, there are a number of variables that needed to be controlled in order to achieve the main objective of the study, which included variables such as, feedstock preparation and moisture content of the mixtures. It is imperative that, from the Coalgae ${ }^{\circledR}$ mixtures mixed and centrifuged at the same time to obtain pellets with high compression resistance, the sample moisture should be slightly higher at around $22 \%$ to get stronger pellets from the mixture that was left starring and centrifuged after 24 hours, the moisture content should be lower at around $17 \%$.

\section{Acknowledgements}

This research was supported by the National Research Foundation and the Nelson Mandela University Institute for Chemical Technology.

\section{References}

ASTM D2013: Standard method of preparing coal samples for analysis.

ASTM_D3173: Standard test method for moisture in the analysis sample of coal and coke.

ASTM_D3175: Standard test method for volatile matter in the analysis sample of coal and coke.

ASTM D3172: Standard practice for proximate analysis of coal and coke.

ASTM_D3174: Standard test method for ash in the analysis sample of coal and coke.

Cai, J., He, Y., Yu X., Banks S. W., Yang, Y., Zhang, X., Yu, Y., Liu, R. and Bridgwater, A. V. 2017. Review of physicochemical properties and analytical characterisation of lignocellulosic biomass. Renewable and Sustainable Energy Reviews, 76, 309-322. https://doi.org/10.1016/j.rser.2017.03.072

Table 4: Impact resistance index of the pellets.

\begin{tabular}{|c|c|c|}
\hline Sample ID & $\begin{array}{c}\text { IR at } 3500 \mathrm{psi}, \\
\text { sample moisture }= \pm 17 \%\end{array}$ & $\begin{array}{c}\text { IR at } 3500 \mathrm{psi} \\
\text { sample moisture }= \pm 22 \%\end{array}$ \\
\hline Pure coal & 50.0 & 68.9 \\
\hline Coal $_{90 \%}$-algae $10 \%$ mix (mixed \& centrifuged) & 125.0 & 133.3 \\
\hline Coal $_{80 \%}$-algae $20 \%$ mix (mixed \& centrifuged) & 88.9 & 81.3 \\
\hline Coal $_{90 \%}$-algae ${ }_{10 \%}$ mix (centrifuged after 24 hours) & 153.8 & 105.3 \\
\hline Coal $_{80 \%}$-algae $20 \%$ mix (centrifuged after 24 hours) & 105.3 & 133.3 \\
\hline $\mathrm{IR}=$ impact resistance & & \\
\hline
\end{tabular}


Diez, M.A., Alvarez, R. and Cimadevilla, J.L.G. 2013. Briquetting of carbon-containing wastes from steelmaking for metallurgical coke production. Fuel, 114, 216-223.

https://doi.org/10.1016/j.fuel.2012.04.018

Easby W. 1848. Method of converting fine coal into solid lumps. United States patent office. Patent No. 5,739 .

Eskom.co.za/OurCompany/CompanyInformation/Pages/ Company_Information.aspx

Gaqa S., Mamphweli S., Katwire D. and Meyer E. 2014. The properties and suitability of various biomass/coal blends for co-gasification purposes. Journal of Sustainable Bioenergy Systems, 175-182.

Hancox, P.J. and Götz, A.E. 2014. South Africa's coalfields - A 2014 perspective. International Journal of Coal Geology, 132, 170-254.

https://doi.org/10.1016/j.coal.2014.06.019

NREL/TP-510-42621: Sluiter A., Hames B., Hyman D., Payne C., Ruiz R., Scarlata C., Sluiter J., Templeton D. and Wolfe J. 2008. Biomass and Total Dissolved Solids in Liquid Process Samples.

Parikh, J., Channiwala, S. and Ghosal, G. 2005. A correlation for calculating HHV from proximate analysis of solid fuels. Fuel, 84(5), 487-494.

Parikh, J., Channiwala, S. and Ghosal, G. 2005. A correlation for calculating HHV from proximate analysis of solid fuels. Fuel, 84(5), 487-494.

RIchards S.R. 1990. Physical testing of fuel briquettes. Fuel Processing Technology. 25, 89-100.

South Africa River Energy, 2013. The formation of River Energy SA, 38-40.

Saikia, M. and Baruah, D. 2013. Analysis of physical properties of biomass briquettes prepared by wet briquetting method. International Journal of Engineering Research 6(5), 12-14.

World Energy Council. 2013. Technical Report, Energy efficiency technologies Annex 1 - Energy efficiency potentials and barriers for realisation in the industry sector.

Zeelie B., (Nelson Mandela Metropolitan University) 2013. Upgrading coal fines using microalgae. South Africa Patent Application, 2013/03681. 